\title{
Cultural Landscapes, Ecological Restoration and the Intergenerational Narrative
}

Link to publication record in Manchester Research Explorer

\section{Citation for published version (APA):}

Knights, P., Drenthen, M. (Ed.), \& Keulartz, J. (Ed.) (2014). Cultural Landscapes, Ecological Restoration and the Intergenerational Narrative. In Old World and New World Perspectives on Environmental Philosophy: Transatlantic Conversations (1 ed., pp. 93-108). Springer Nature.

\section{Published in:}

Old World and New World Perspectives on Environmental Philosophy

\section{Citing this paper}

Please note that where the full-text provided on Manchester Research Explorer is the Author Accepted Manuscript or Proof version this may differ from the final Published version. If citing, it is advised that you check and use the publisher's definitive version.

\section{General rights}

Copyright and moral rights for the publications made accessible in the Research Explorer are retained by the authors and/or other copyright owners and it is a condition of accessing publications that users recognise and abide by the legal requirements associated with these rights.

\section{Takedown policy}

If you believe that this document breaches copyright please refer to the University of Manchester's Takedown Procedures [http://man.ac.uk/04Y6Bo] or contact uml.scholarlycommunications@manchester.ac.uk providing relevant details, so we can investigate your claim.

\section{OPEN ACCESS}


This is a pre-copy-editing, author-produced PDF of an article accepted for publication in Martin Drenthen and and Jozef Keulartz (eds) 2014. Old World and New World Perspectives on Environmental Philosophy:

Transatlantic Conversations. London: Springer, pp. 93-108.

The definitive publisher-authenticated version is available online at http://www.springer.com/us/book/9783319076829

(C) 2014 Springer

\section{Cultural Landscapes, Ecological Restoration and the Intergenerational Narrative}

The dominant goal of nature conservationists is the conservation of biodiversity. In the UK, and throughout the "Old World" of Europe, the principal means through which this goal has been achieved is the preservation and restoration of traditional cultural ecosystems. This paper has two purposes. Firstly, it is intended to contribute to the recent attempt to shift philosophical scrutiny from the restoration of natural ecosystems to the species of restoration practice that takes place within cultural landscapes. Secondly, I will argue that much of value and meaning will be lost - value and meaning that ought to be considered in deliberations over the adoption of alternative conservation strategies - if the preservation and restoration of traditional cultural ecosystems is forsaken. Section 1 questions the appropriateness of the demand - familiar from Robert Elliot's arguments concerning restored natural ecosystems for restored cultural ecosystems to be authentic instances of original, pre-degradation cultural ecosystems. Section 2 will argue that, despite the demand for authenticity being unjustified in relation to the stated biodiversity goals of conservationists, authenticity is often achieved to a considerable extent and, as such, the work of restorationists is valuable insofar as they are preserving items of cultural heritage. Section 3 grounds a distinct ethical argument for the restoration of cultural ecosystems in this overlooked value of the practice. Section 4 concludes by considering, in light of the foregoing arguments, the implications for cultural 
ecosystems and the value of their restoration of the recent pursuit of alternative biodiversity conservation strategies. I begin with a brief introduction to cultural ecosystems and restoration practice.

The European landscape is a cultural landscape. Cultural landscapes are mosaics of cultural ecosystems, and a cultural ecosystem is "one that has developed under the joint influence of natural processes and human-imposed organisation."1 Examples are meadows, pasture, lowland heath, wood pasture, reedbeds, upland moor and coppice woodland. They were created and maintained - by grazing, burning or cutting - for a variety of agricultural, industrial and recreational reasons. To restore a cultural ecosystem is to initiate or accelerate the recovery of a damaged, degraded, transformed or destroyed cultural ecosystem. ${ }^{2}$ This restoration may be necessary either because traditional land use practices have been abandoned and no alternative practices have replaced it such that natural processes are increasingly governing the site's ecological trajectory, or because traditional land use practices have been abandoned in favour of modern agricultural practices. Depending on the extent of degradation the ecosystem has been subject to, extraordinary measures that are not among the repertoire of traditional practices may have to be employed before traditional land management techniques to maintain the ecosystem in its desired state can resume. In cases where traditional management has been abandoned in favour of agricultural improvement involving cereal crops or re-seeded swards of highly productive pasture grasses, nutrient rich topsoil may need to be removed to allow the re-establishment of grassland species requiring poorer nutrient conditions, or direct sowing of heathland species may be called for where the existing seedbank is exhausted. In cases where cultural ecosystems are degraded as a result of neglect rather than improvement, reedbeds, fens and grassland may need to be burnt to remove litter build-up and rank vegetation; ${ }^{3}$ scrub, trees or bracken may need to be removed 
from heathland or reedbed by mechanical or herbicidal means; ${ }^{4}$ or grassland may require mechanical soil disturbance to enable re-colonisation. ${ }^{5}$

Three broad approaches are employed to achieve the restoration and maintenance of traditional cultural ecosystems. Firstly, the involvement of conservation organisations in a restoration project may be limited to assisting a land manager - for example a farmer - in applying for a government subsidised agri-environmental scheme, such as the UK's Environmental Stewardship scheme. ${ }^{6}$ Secondly, a conservation organisation may take ownership of a cultural ecosystem but keep on existing farmers, making it a condition of their tenancy that they adopt traditional land management practices that result in the restoration and maintenance of the desired cultural ecosystems and thereby the protection of their associated biodiversity. Thirdly, conservation organisations may take ownership of a cultural ecosystem but, instead of employing resident land managers, merely mimic traditional land management practices, using volunteers and employees instead of farmers and other land managers. It is this last approach that will be the focus of this paper.

\section{The Demand for Authenticity}

Some of the earliest reflections of environmental philosophers on the practice of ecological restoration produced two criticisms which centred on the ontological status of restored ecosystems. One criticism - from Eric $\mathrm{Katz}^{7}$ - was that restored ecosystems are artefacts. The other - from Robert Elliot ${ }^{8}$ - was that restored ecosystems are fakes. Even though Elliot's criticism was aimed at the restoration of natural ecosystems, it provides a useful conceptual framework to investigate the ontological status - and the corresponding account of authenticity - of restored cultural ecosystems. I will reject Elliot's criticism and argue that the 
demand for authenticity in restored cultural ecosystems is too demanding in relation to the stated biodiversity goals of conservationists.

Elliot argues that for ecological restorationists to succeed in restoring a natural ecosystem it would be necessary for them to restore the following properties:

(i) the non-relational property of according with a natural design;

(ii) the non-relational property of being constituted by natural items;

(iii) the relational property of being the product of natural processes;

(iv) the relational property of having a natural and unbroken continuity with the distant past. ${ }^{9}$

Elliot believes that properties (i) and (ii), like other non-relational properties such as beauty, diversity, integrity and complexity, can in principle be restored. However, he claims that properties (iii) and (iv) cannot in principle be restored. Property (iii) cannot be restored because the human practice of ecological restoration involves at least some technological processes; a restored ecosystem can therefore never entirely be the product of natural processes. Property (iv) cannot be restored once it is broken simply because the past is outside our control. Therefore, restored ecosystems - even ones that accord with a natural design; are constituted by natural objects; and bear all the other non-relational properties that the original ecosystem possessed - are fakes, since they necessarily fail to bear relational properties (iii) and (iv).

Elliot's claims have received much unfavourable attention from restoration practitioners. ${ }^{10}$ Although cultural ecosystem restoration is a kind of restoration that Elliot appears to be 
unaware of - his arguments exclusively address the products of the practice of natural ecosystem restoration ${ }^{11}$ - his arguments have nonetheless been interpreted as applying to restored cultural ecosystems and have thereby disenchanted restoration practitioners as to the possible contribution environmental philosophy may make to restoration theory and practice. Despite later developing a concise and helpful typology of restoration projects which distinguishes faking - the creation of a replica of some particular object and the representation of that replica as the original - from restoring - bringing a damaged object back to its original condition - Elliot continues to use the term "faked nature" to refer to restored ecosystems. He justifies this continued use by pointing to the way that the term draws attention to the normative significance of natural origin, even where there is no deception involved. ${ }^{12}$ Since Elliot continues to refer to restored ecosystems as faked nature, I think the criticism's application to restored cultural ecosystems needs to be considered. I will do this by considering what features of a given cultural ecosystem that has been subject to restoration would lead us to conclude that - despite a disruption in its continuity with the distant past - it remains an authentic instance of a cultural ecosystem of its type.

Consider a heathland whose management by burning and cutting was abandoned during the period of the Black Death. ${ }^{13}$ As the population recovered to its pre-pandemic level, formerly cultivated land was reclaimed from the succeeding woodland and cultural ecosystems were restored. ${ }^{14}$ After 25 years the heathland is in a considerably degraded state, with much dwarf shrub, grass and birch encroachment replacing the heather-dominated vegetation. However, it is not so degraded that we would say it was no longer the same ecosystem as existed before abandonment. When members of the local population clear away the scrub and young birch, resume harvesting and bruning the bracken and once again graze livestock, the heathland is restored to a condition very close to that prior to its abandonment. This is an instance of what 
Elliot calls "token-restoration", where a particular object that has been degraded or damaged is brought back closer to a past condition. ${ }^{15}$ I would argue that the result of that restoration is a perfectly authentic, i.e. non-fake, cultural ecosystem. Firstly, being an instance of tokenrestoration, it possesses the relational property of having an unbroken (albeit temporarily disrupted) continuity with the distant past. (If it had taken the local population longer to return to the heathland and it had fully succeeded into woodland such that it would no longer be appropriate to say that it is the same cultural ecosystem as existed before its abandonment then only "type-restoration" would be possible.) Secondly, it accords with a certain design of cultural ecosystem, consisting in a certain species composition, structure and management regime. This is analogous to Elliot's naturalness property (i), the non-relational property of according with a certain natural design. Thirdly, it was restored using the very same land management practices which had maintained the ecosystem before the disruption. Fourthly, the restoration of the heathland was executed for the very same reasons that drove the creation and maintenance of the ecosystem prior to its disruption, namely, to derive a livelihood. Lastly, it was restored by the very same community that created and cultivated the ecosystem prior to its disruption; we can imagine that surviving members of the same family that managed the land prior to the disruption returned and restored it.

The claim that the above example was of a restored cultural ecosystem which achieved authenticity was that the following properties - in addition to unbroken continuity with the distant past - were restored:

(i) accordance with a traditional cultural design;

(ii) being the product of traditional techniques and tools; 
(iii) being the product of a certain human motivation (namely, the motivation to derive a livelihood);

(iv) being the product of a certain human community.

Elliot's criticism of the practice of ecological restoration was that its products were fakes. However, when considering the implicit demand for maximal authenticity that this places on restoration practitioners working in Old World cultural landscapes, it seems both unfair and inappropriate to demand that the above properties are restored given that their goal is the maintenance and enhancement of biodiversity. While broad accordance with a cultural design will be necessary to preserve the biodiversity the species-level biodiversity that the ecosystem supports and the ecosystem-level biodiversity that it embodies, the other properties are not necessary to restore in order to meet their objective. The conception of authenticity that does so require them is unjustifiably demanding. However, despite the unwarrantedly demanding conception of authenticity that has emerged from transferring Elliot's arguments to the practice of cultural ecosystem restoration, it is nonetheless often the case that properties (ii), (iii) and (iv) are restored to some extent by conservation organisations; many conservation organisations $d o$ use traditional techniques and tools, many members of communities with long associations with the cultural ecosystems undergoing restoration are involved in the work, and sometimes the more traditional motivation of deriving an income is woven into restoration projects. In the next section I will examine the value of restoration projects which meet the more demanding conception of authenticity. 


\section{The Demand for Full-value Restoration}

This section is an examination of the value possessed by restored ecosystems that meet the more demanding conception of the authenticity of restored cultural ecosystems. As I argued above, although it is unjustifiable to require conservation organisations who engage in the restoration and subsequent management of cultural ecosystems to adhere to the robust conception of authenticity that may be derived from Elliot's arguments, they frequently succeed in doing so. That is, to achieve their stated goal of the conservation of biodiversity it is only necessary that they restore property (i) - adherence to a certain cultural design - in order to conserve the biodiversity that the ecosystem supports and embodies. But despite the restoration of properties (ii), (iii) and (iv) - techniques and tools, motivation, and community - being to a large extent unnecessary for the achievement of their stated purpose, conservation organisations frequently do restore these properties. I will again use the arguments developed by Elliot in relation to the restoration of natural ecosystems as a helpful frame for the discussion. I will argue that Elliot's claim that ecological restoration projects should be judged according to the standard of "full value" restoration is not only - like the requirement for authenticity - unduly demanding, but also inappropriate due to the peculiar way items of cultural heritage are valued.

Elliot distinguishes full value restoration from equal value restoration, and claims that full value restoration is what is desirable. Full value restoration, for Elliot, would be accomplished "not merely [by] creating something equal in value to something else that has been degraded or destroyed, it would also involve achieving that equal quantity of value by creating something with the very same pattern of value-adding properties earlier possessed by the thing degraded or destroyed." 16 Value-adding properties are those properties such as 
complexity and beauty that, other things being equal, function to increase the overall value of the thing that possesses them. ${ }^{17}$ Again, we must ask whether this demand for full value restoration is appropriate for the restoration of cultural, as opposed to natural, ecosystems. ${ }^{18}$

Cultural ecosystems possess many kinds of value, each grounded in a particular set of valueadding properties. Firstly, aesthetic value has been attributed to cultural ecosystems from the time of the Romantic poets. Indeed, it is this aesthetic value that motivates much of the current effort to preserve cultural ecosystems and landscapes. More recently, recreational or amenity value has been attributed to cultural ecosystems on the basis of the opportunities they provide for such activities as walking, mountain biking, bird watching and other forms of outdoor recreation. Ecosystem service value is attributed to cultural ecosystems on the basis of their role in providing services such as nutrient recycling, pest control, soil production, water purification and erosion and flood control. ${ }^{19}$ Cultural ecosystems are also of scientific value in virtue of the potential study of their resident nonhuman organisms, and of the ecological relationships that obtain between them and the abiotic environment and human management activities. Biodiversity value is, as I have observed, the value that conservation organisations are explicitly working to conserve and restore.

If Elliot's criticism that restored natural ecosystems possess less value than original, predegradation natural ecosystems is to transfer to the case of restored cultural ecosystems then it has to be the case that there are some value-adding properties of original, pre-degradation cultural ecosystems - and therefore the classes of value that these properties ground - that cannot be restored. It seems to me that full value restoration can be achieved for each of the above kinds of value. Firstly, I think it is uncontroversial to claim that the value-adding properties on which the attribution of economic and recreational or amenity value is based 
can be restored; numerous landscape restoration projects intended to support the economy of, and recreational opportunities afforded by, the National Parks of the UK are engaged in by their respective Authorities. Secondly, the value-adding properties that ground the attribution of biodiversity value are, as I have argued, the principal objective of the restoration of cultural ecosystems engaged in by UK nature conservation organisations, who regularly claim to have either restored the same level of, or even increased, the biodiversity of their nature reserves. If this is the case, then the ecosystem service and scientific values based on the presence of biodiversity may also be restored. The restoration of the value-adding properties on which attributions of aesthetic value are grounded is potentially more difficult, depending on how broad a conception of aesthetic properties one has. I will not pursue this issue further here, but I believe it is plausible to claim that full value restoration can be achieved regarding the above classes of value.

However, cultural ecosystems possess another kind of value which I will argue that it would be undesirable to fully restore, namely, cultural heritage value. This kind of value is borne by objects that are of historical importance in the culture of a region or nation. The traditional cultural ecosystems that have survived the degradation and destruction of the past 75 years have become important and rare embodiments of our agricultural and social history. The value-adding properties that ground this kind of value attribution are the very ones that we have been examining with regard to the ontological status of restored cultural ecosystems; having an unbroken continuity with its pre-degradation self, accordance with a traditional cultural design, being the product of certain tools and techniques, being the product of a certain human motivation and being the product of a particular human community. I argued that it is unfair and inappropriate to level an accusation of fakery at conservation organisations for failing to restore these properties since they are understandably concerned 
primarily with property of accordance with traditional cultural designs in relation to their stated goal. I also noted, however, that these properties frequently are restored. In so doing, conservationists not only succeed in restoring those properties that ground attributions of biodiversity value to cultural ecosystems, but also those for cultural heritage value. We can now enquire as to whether there is any reason to strive for the full restoration of the latter class of value.

Consider a scenario in which a conservation organisation takes ownership of two degraded coppice woodlands with the intention of restoring them for their biodiversity value. Both have been neglected for some years and are in a degraded state; the coppice stools have been left for some time past their optimal 10-year cutting cycle and, as a consequence, the diversity and abundance of ground flora is diminishing as the shading canopy increases. One of the woodlands is restored to a non-traditional cultural design (for example, it is put onto a 25 year, rather than 8-15 year, felling cycle), using chainsaws to fell the trees and tractors to extract the timber. The organisation's employees and non-local contractors execute the work, and once the timber is extracted it is burnt or otherwise discarded. The other woodland is restored in accordance with an established cultural design, using traditional woodland hand tools called billhooks and horses to extract the timber. Volunteer members of the local community whose predecessors have a long association with the woodland execute the work under the guidance of the staff of the conservation organisation, and the timber is worked by local craftspeople into "hurdles" (fencing panels), tool handles and baskets, or made into charcoal, and the products are sold locally. The former woodland, in deviating from the traditional cultural design of coppice woodlands - particularly a felling cycle that is determined by the usefulness of the products that can be made from its timber - warrants a lesser attribution of cultural heritage value than the latter. 
Consider that property (iii) - the property of being the product of a certain motivation, namely, to derive a livelihood - is not fully restored in the latter of the above examples. This is not only because I wanted my example to reflect current practice in UK conservation, but also because it is unlikely that an item of cultural heritage that fully restored property (iii) would be valued as such. The motivation of our predecessors to create and maintain the cultural ecosystems that we now desire to restore for the sake of biodiversity would have been closer to the motivation to merely survive, which is quite different from the motivation of the people in my example. If visitors to the woodland found not contented downsizers who have freely chosen to try their hand at making a modest living from the sale of their products, but bonded serfs impelled by a lack of alternatives or the threat of starvation, they would be unlikely to congratulate the conservation organisation for their full restoration of property (iii) and attribute a greater quantity of cultural heritage value to the woodland. The cultural heritage value attributed to an object may well be partly grounded in the recognition of the circumstances of, and motivation for, its creation, but if the object is damaged and we desire to restore it, this is not to say that we would necessarily desire it to be restored in the very same circumstances and for the very same motivation. Cultural heritage value is mostly attributed to objects, traditions and environments that have become somewhat divorced from the circumstances of their creation and historical use; to label something as an item of heritage implies that its time has passed, though this need not necessarily be so. But we also desire to understand and honour our heritage by preserving it and, where appropriate, engaging with it in some limited way. ${ }^{20}$ While some items of heritage can only be appropriately preserved, and thus honoured, in museums, many items can be used; vintage cars can be driven, Spitfires flown and handlooms spun. Further, much of our heritage is not constituted by objects, but by activities. The woodland crafts referred to can be tried by the curious and taken up by the avid, and in this way honoured as part of our heritage. Lastly, 
among those things that constitute cultural heritage are the attitudes, ideas, aspirations and, indeed, motivations of our predecessors. Again, these may be honoured by attempting to understand them and, if they are found valuable, perhaps adopting them. But not in all cases will we find them valuable or desirable, even if we come to understand why our predecessors did. And in some cases, although part of our cultural heritage and for that reason valuable, the motivations and circumstances of some of our cultural ecosystems will not be such that we judge restoration of them to be desirable. Those who take up the woodland crafts and derive a small income from them are, in a limited way, engaging with their heritage by sharing the motivation with their predecessors to derive an income. Visitors to the woodland may find additional value in it as an item of cultural heritage value when they discover that some of the people who work the wood are making a living from it (and better still if they learn that they are descendents of those who worked in the wood in decades or centuries past). But there is only so far that this kind of authenticity can go before it becomes a disvalue. I conclude, therefore, that due to the peculiar way we value items of cultural heritage, Elliot's demand for full value restoration is inappropriate in many cases of cultural ecosystem restoration.

\section{Cultural Heritage, Narrative and the Intergenerational Contract}

The previous section developed an understanding of cultural ecosystems as items of cultural heritage. In this section I will further develop this theme by applying an ethical argument developed by Janna Thompson - grounded in an intergeneration contract - for the preservation and restoration of items of cultural heritage. I will fortify this proposal with an application of "the narrative approach" as deployed by John O’Neill. I will then apply this argument to the specific case of cultural ecosystems. This argument is intended to supplement the often insufficient appeal to biodiversity value that conservationists make to justify their 
endeavours. As Rackham observes, "[t]he case for conservation is weakened by lack of coordination between those concerned with scenery, wildlife, [and] antiquities". ${ }^{21}$ Where conservation organisations have an opportunity to highlight the opportunities their work provides as a way of connecting our lives to those of our predecessors, a wider constituency may be found to support their efforts. This section is also an attempt to "thicken" the normative discourse with which we might engage in practical deliberation concerning potential conflicts between biodiversity and cultural heritage value. ${ }^{22}$

There are several kinds of items of cultural heritage, each of which are associated with or embody the history of a community of people; objects (buildings, monuments, artworks, artefacts), traditions (crafts, festivals, games, cuisine, fashions, dances, livelihoods, ideologies, motivations, attitudes) and environments, such as the lanes between the terraced houses of coal mining towns, the gardens of stately homes, drove roads, industrial environments and, of course, the cultural ecosystems that are the focus of this paper. The item may symbolise a movement, period or important historical event; have been valued or disvalued by past generations; or have had a formative influence on the character and deeds of members of the community. ${ }^{23}$ The reasons advanced to justify the preservation of an item of cultural heritage are often aesthetic, economic or educational. However, Thompson has developed an ethical justification grounded in an intergenerational contract, which she applies to the case of natural environments. This contract is grounded in the posterity-related desires that each generation has concerning their legacy - a historical narrative embodied within objects, traditions and environments - to their successors (249). Our posterity-related desires concerning this legacy include the desires that our successors value, preserve and, where necessary, restore the objects that we leave them; continue the projects, traditions and institutions that we pass on to them (251-2); and endeavour to understand and appreciate our 
values, deeds and characters (249). Such a desire requires of our successors that they do not wilfully or ignorantly destroy, but rather preserve and pay respectful attention to, the objects, traditions and environments that embody significant elements of the historical narrative that we leave them (255). The significant elements will be those that (i) we valued, cherished, protected and wanted our successors to inherit, or (ii) had a significant influence on our values, deeds and characters (even if we did not value or, further, even if we actively disvalued them). Firstly, the fact that we valued the object, tradition or environment provides our successors with a reason to seek to understand and appreciate why it was so valued. Such appreciation cannot be gained from imagination or from historical records; it requires that the object, tradition or environment itself be preserved, and that respectful attention is paid to it (251). Secondly, Thompson argues that to fully respect our legacy requires of our successors that they understand their lives as a continuation of the narrative that we pass on to them, and that they understand their values, deeds and characters in relation to a history in which ours are accorded due recognition (255-6). Thompson argues that the failure to preserve a particular object, tradition or environment that we valued, or to fail to respect the legacy by refusing acknowledgment of the way in which their values are shaped by those of their predecessors (i.e. our values) is a manifestation of a moral fault in our successors such as discourtesy or impiety (252). The destruction of the objects and environments, and the discontinuation of the traditions that we bestowed upon them is a manifestation of the refusal of such acknowledgment. The content of the intergenerational contract invoked by Thompson, then, is constituted by the acceptance of the following by each generation: if we believe that our successors have an obligation with respect to us to (i) seek to understand and appreciate our values by preserving and paying respectful attention to the objects, traditions and environments that we have treasured, and (ii) preserve and pay respectful attention to the objects, traditions and environments that have had a significant influence on our values, 
deeds and characters, then we have a corresponding obligation with respect to our predecessors (249).

Thompson's argument, while persuasive, relies largely on the "thin" normative concept of obligation and a metaethical commitment to impartiality. To enrich the normative discourse we could deploy to articulate the argument that we ought to respect our predecessors' legacy I will augment Thompson's account with a further claim which she rejects the need for; the claim that the dead can be wronged (249). As O'Neill has argued in the context of a discussion of our obligations with respect to future generations, the belief that the deceased can be harmed or benefited has only recently been abandoned for a "temporally local perspective on our goods [which] is founded on a pervasive but mistaken view of what goods and harms can befall us - that only that of which we are aware can harm us". ${ }^{24}$ To make this argument we can employ a notion that already comprises an element of Thompson's account of the intergenerational contract, namely, narrative. Consider the life of an individual as a narrative. "Narratives", O’Neill explains, "do more than describe lives; they contain an evaluative component about how well those lives went". ${ }^{25}$ One way of conducting this evaluation is to determine which genre - tragic, comic, heroic, and so on - the narrative belongs to, and this determination can be made "only from the viewpoint of the end of the story." ${ }^{26}$ For example, one can never be sure whether a narrative is a tragedy unless one knows how it ends. Crucially, the end of a person's life may not be the end of their life-story, and therefore not the proper point from which to conduct its evaluation. Many of our projects transcend the scope of our own lives; we constitute societies, found charities, campaign for legislation and conduct research into cures for diseases. The success or failure of these longterm projects is dependent on the decisions and actions of our successors. The narratives of our lives continue as long as the projects with which we were associated continue. For 
example, the passing of the legislation after our death for which we long campaigned may render our life a success; our successors have benefited us in rewarding and honouring our efforts with that which we most desired. But if our successors subsequently misuse the legislation for purposes antithetical to those for which we advocated it, they have harmed us by realising our worst fears, disrespecting our wishes and wrongly associating our name with something we would consider disgraceful; our life-narrative is rendered tragic. This narrative approach to the evaluation of a person's life allows us to see that the living can benefit or harm the dead. Moreover, this benefit or harm can be articulated in a rich normative discourse, employing "thick" ethical concepts such as disrespect, dishonour, discourtesy and their opposites. While Thompson does invoke such evaluative terms, it is difficult to see how we can wrong our predecessors if, as she claims, they have no rights or interests. ${ }^{27}$ This argument justifies the attribution of such vices by acknowledging that the dead can be wronged. It can then be employed to augment Thompson's argument for the existence of an intergenerational contract; not only can we appeal to the metaethical commitment to impartiality to ground our obligations to respect the legacy of our predecessors, but also to the harm or benefit we can do them in the manner we continue their narrative.

I have argued until now for the preservation and restoration of items of cultural heritage in general. Let me now apply these arguments to the specific case of the cultural ecosystems that are the subject of this paper. Firstly, recall that the intergenerational contract imposes an obligation on us to (i) seek to understand and appreciate the values of our predecessors by preserving (and, where necessary, restoring) and paying respectful attention to the objects, traditions and environments that they valued, and (ii) preserve (and, where necessary, restore) and pay respectful attention to the objects, traditions and environments that had a significant influence on our predecessors' values, deeds and characters. With regard to (i), it is clear that 
our predecessors would have attributed certain values - economic value and inheritancelegacy value 28 - to the cultural ecosystems that they created, cultivated and inhabited. That they did so imposes obligation (i) on us, their successors; the obligation to endeavour to understand and appreciate the genesis and nature of these values, and their manifestation in their deeds of creating, cultivating and, in extraordinary circumstances such as during the Enclosure Acts of the $18^{\text {th }}$ and $19^{\text {th }}$ centuries, protecting them. With regard to (ii), it seems clear that the cultural ecosystems that are currently preserved and restored by conservation organisations for the sake of their biodiversity value had a significant influence on the character and activities of our predecessors; the cultural ecosystems that are our concern are of considerable antiquity ${ }^{29}$ and any account of the history of a community or region of the Old World, or indeed of the history of the region itself, is unlikely to be complete without significant reference to them. The relationships that our predecessors had with the cultural ecosystems they created, cultivated and inhabited were pervasive; they bestowed vernacular names upon their constituent species which then re-entered the language with new meanings associated with that which they labelled; children's games were woven around the plants and animals they encountered there; wild species were harvested from them and formed the basis of local cuisines; places were named after them; ${ }^{30}$ political causes were fought in and over them; medicinal plants were cultivated in and harvested from them; folklore and mythology surrounded them; and they determined much of the development of skills and crafts. ${ }^{31}$ That our predecessors had such rich relationships with these ecosystems imposes obligation (ii) on us; to understand cultural ecosystems as the source of these influences and to appreciate how these influences have resonated throughout the narrative which we are continuing requires that we preserve and, where necessary and possible, restore cultural ecosystems. And again, the argument that such obligations are imposed upon us can be supported by reflecting on the harm we do our predecessors by failing to meet them; in destroying the cultural ecosystems 
that they created and allowing the skills and crafts that they cultivated for their management to be lost from memory we end their narrative (and I think it is fair to say that their narrative ends here) in a sorrowful way. In common with $\mathrm{O}^{\prime} \mathrm{Neill},{ }^{32} \mathrm{I}$ do not wish to suggest that every embodiment of the narrative of our predecessors must be preserved and restored, but where the burden is not great - for we must acknowledge that our successors will have problems and priorities of their own such that we cannot reasonably demand they unconditionally respect our legacy - the obligations of the intergenerational contract, and the recognition that we can harm or benefit our predecessors, ought to motivate us to preserve and restore traditional cultural ecosystems.

In summary let us return to the traditionally restored coppice woodland to illustrate the narrative-augmented intergenerational contract argument for the preservation of cultural ecosystems qua items of cultural heritage. The conservation organisation is manifesting respectfulness toward our predecessors; in restoring the coppice woodland in accordance with the design created and maintained by past generations, employing traditional techniques and tools, allowing volunteers from the local community to be involved in the restoration and to engage in traditional crafts, it is providing opportunities for understanding and appreciating the hardships our predecessors must have endured and the pleasures they must have taken in their lives lived in daily struggle against, as well as intimate cooperation with, natural processes. Furthermore, it is restoring an environment that, in a long history of association that stretches back to the Neolithic and that has only recently been abandoned, shaped and influenced the lives of our predecessors. And in restoring the woodland we are ensuring that the narratives of the individuals whose lives were lived in intimate association with it are not ended tragically. In contrast, the pursuit of higher biodiversity value at the non-traditionally 
restored woodland, while in the pursuit of a worthy goal, manifests disrespectfulness toward our predecessors by failing to preserve that which they created and valued.

\section{New Challenges for Traditional Cultural Ecosystems}

It is rare for conservation organisations to explicitly justify their activities by appeal to the heritage value of either the cultural ecosystems they preserve and restore or of the management practices they employ. My examination of the practice of cultural ecosystem restoration suggests that conservationists would be well advised to accept and embrace this value of their work. But as things currently stand, it is the conservation and enhancement of biodiversity that motivates the preservation and restoration of cultural ecosystems and thereby - inadvertently but undeniably - protects important items of cultural heritage and thereby respects the legacy of our predecessors. But conservationists are increasingly advocating alternative means of achieving their goal. Firstly, an approach called "creative conservation" is increasingly being adopted whereby instead of the "direct mimicry of some target community that once existed" the intention is to establish "essentially new and indeterminate communities and habitats"33 that "may have similarities with the old but are essentially a product of a different time, just as hay meadows were a product of their own tradition." 34 This approach is intended to be a movement away from the "slavish adherence" to traditional management and the assumption that our predecessors' management of cultural ecosystems was always benign or beneficial for biodiversity and thus should be mimicked. ${ }^{35}$ Secondly, in recent years a new conservation strategy - rewilding - has emerged. ${ }^{36}$ Rewilding emphasises the restoration of large areas, the granting of free reign to natural processes, the withdrawal of human management and the reintroduction of large herbivores and top predators. This strategy is gaining supporters among both Old and New World 
conservationists for two reasons relating to biodiversity. The first is that recent ecological research emphasises the importance of the top-down regulation exerted by species occupying the highest trophic levels (i.e. top predators) for biodiversity. ${ }^{37}$ The anticipation of the reintroduction of large predators justifies the rewilding approach's emphasis on large areas of wild land. The second, also justifying larger conservation areas, is that climate change is anticipated to have a catastrophic effect on components of biodiversity dependent on small nature reserves isolated within a wider, inhospitable agricultural environment. Both creative conservation and rewilding are clearly incompatible with the preservation and restoration of traditional cultural ecosystems. The very motivation that has been responsible for their protection until now - the conservation of biodiversity - appears poised to constitute an additional threat to the perpetuation of their role in our narrative. I hope I have shown that much of value and meaning will be lost - value and meaning that ought to be considered in deliberations over the adoption of alternative conservation strategies - if the preservation and restoration of traditional cultural ecosystems is forsaken. 
1. Society for Ecological Restoration International Science \& Policy Working Group, The SER International Primer on Ecological Restoration (Tucson: Society for Ecological Restoration International, 2004), 5. I acknowledge that the ecosystem concept has been the subject of criticism in recent years (see, for example, Robert V. O’Neill, “Is It Time to Bury the Ecosystem Concept? (With Full Military Honors, Of Course!)," Ecology 82 (2001): 3275-84 and S. T. A. Pickett, V. T. Parker and P. L. Fiedler, “The New Paradigm in Ecology: Implications for Conservation Above the Species Level," in Conservation Biology: The Theory and Practice of Nature Conservation, Preservation and Management, eds. P. L. Fiedler and S. K. Jain (New York, N.Y.: Chapman \& Hall, 1992), 261-78. Moreover, the concept of a cultural ecosystem is not well articulated within the ecological literature. However, my extensive employment of the ecosystem concept (in references to both natural and cultural ecosystems and their restoration), rather than, say, the landscape concept, is intended to reflect the fact that ecological restoration is a practice largely guided by ecological science rather than, say, aesthetic criteria. Also, I think it fair to say that most restoration practitioners would claim that what they are restoring are ecosystems.

2. As the SER points out, much restoration activity will be directed toward "the reintegration of fragmented ecosystems and landscapes, rather than focusing on just a single ecosystem.” (Society for Ecological Restoration, Primer, 5.) I will, however, continue to refer to "cultural ecosystem restoration" in the singular for the sake of simplicity and clarity. This is to be understood, where appropriate, as implicitly encompassing the (almost certainly more common practice of the) restoration of multiple cultural ecosystems or the restoration of a cultural landscape (i.e. a mosaic of cultural ecosystems).

3. For reedbed, see N.Burgess, D. Ward, R. Hobbs and D. Bellamy, "Reedbeds, fens and acid bogs," in Managing Habitats for Conservation, eds. William J. Sutherland and David A. Hill (Cambridge: Cambridge University Press, 2005), 183. For fen, see Burgess et. al., "Reedbeds,” 184. For grassland, see D. A. Ausden and J. Treweek, "Grasslands," in Sutherland and Hill, Managing Habitats, 220-21.

4. For heathland, see P. M. Dolman and R. Land, "Lowland heathland," in Sutherland and Hill, Managing Habitats, 276. For fen, see Burgess et. al., "Reedbeds," 184.

5. Ausden and Treweek, "Grasslands," 221.

6. Natural England, "Environmental Stewardship," page accessed on January 72012 , http://www.naturalengland.org.uk/ourwork/farming/funding/es/default.aspx 
7. Eric Katz, "Artefacts and Functions: A Note on the Value of Nature," Environmental Values 2 (1993): 223-32; Eric Katz, Nature As Subject: Human Obligation and Natural Community (London: Rowman and Littlefield Publishers Ltd, 1997).

8. Robert Elliot, "Faking Nature," Inquiry 25 (1982): 81-93; Robert Elliot, Faking Nature (London: Routledge, 1997).

9. Elliot, Faking Nature, 132.

10. Andrew Light, "Restorative Relationships: From Artifacts to "Natural" Systems," in Healing Nature, Repairing Relationships: New Perspectives on Restoring Ecological Spaces and Consciousness, ed. Robert L. France (Cambridge, MA: The MIT, 2005), 101.

11. Examples of natural ecosystems restored in the US are rivers (e.g. the Kissimmee River Restoration Project), wetlands (e.g. the Comprehensive Everglades Restoration Plan) and tallgrass prairie (e.g. the work of the Sauk Prairie Conservation Alliance). There is, of course, increasing evidence that the ecosystems and landscapes that are characterised as natural in the US (namely, those that European settlers encountered in the 18th and 19th centuries) had in fact been the subject of long and significant human disturbance (J. Baird Callicott, "Choosing Appropriate Spatial and Temporal Scales for Ecological Restoration," Journal of Biosciences 27 (2002): 101-112). It may therefore be the case that the ecosystems that are restored by ecological restorationists in the US are not natural in the sense that many have believed they are.

12. After developing the typology in Elliot, Faking Nature on pp. 97-111, Elliot justifies his continuing use of the phrase "faked nature" on p. 132, and employs it again on p. 143.

13. Recent research suggests that the Black Death could have been responsible for Europe's "Little Ice Age" due to the post-pandemic forest regeneration acting as a terrestrial carbon sink. See T.B. van Hoof, F.P.M Bunnik, J.G.M. Waucomont, W.M. Kürschner and H. Visscher "Forest re-establishment on medieval farmland after the Black Death pandemic: implications for atmospheric $\mathrm{CO}_{2}$ levels," Palaeogeography, Palaeoclimatology, Palaeoecology 237 (2006): 396-411.

14. It might be objected that the return of communities affected by the Black Death to reclaim formerly cultivated cultural ecosystems should not be classified as - and considered alongside - the modern practice of ecological restoration. I acknowledge that it is anachronistic to claim that 14th century peasants were carrying out ecological restoration (just as it is anachronistic to claim that they were restoring cultural ecosystems), but I think that it is entirely plausible to claim - and all that needs to be the case for my 
purposes - that they were engaging in restoration. As Jordan observes, restoration is an idea stretching back to biblical times in the fallowing of land (William R. Jordan, III, "Restoration, Community, and Wilderness," in Restoring Nature: Perspectives from the Social Sciences and Humanities, eds. Paul H.

Gobster and R. Bruce Hull (Washington, D. C.: Island Press, 2000), 23).

15. Elliot, Faking Nature, 101-02.

16. Elliot, Faking Nature, 80.

17. Elliot, Faking Nature, 10.

18. It should be noted that Elliot argues that restored (natural) ecosystems necessarily possess less value than original ecosystems since, on his account, not only are there two non-relational properties that cannot in principle be restored (continuity with the distant past and being the product of natural processes), but these very properties are value-intensifying properties, acting "in concert with other properties to produce an overall value well in excess of the sum of the value of those properties, and, for that matter, the value-[intensifying] property itself”' (Elliot, Faking Nature, 81). Restored ecosystems, therefore, will always of necessity be compromised with regard to the value they possess in relation to the original natural ecosystem.

19. Duraiappah, Anantha Kumar and Naeem, Shahid (Synthesis Team Co-chairs), Ecosystems and Human Well-Being: Biodiversity Synthesis, (World Resources Institude, Washington, DC, 2005), 33-7. The services I enumerated are known as provisioning services. Ecosystem service value is, like each of the values I am considering here, attributed to natural as well as cultural ecosystems.

20. As John O’Neill argues, “one major problem with the heritage industry is the way it often attempts to freeze historical development...The object becomes a mere spectacle taken outside of history." (John O’Neill, Ecology, Policy and Politics: Human Well-being and the Natural World (London: Routledge, 1993), 25). This removal from history may take the form of refusing to allow people the opportunity to engage with an item of heritage, even if only in a limited way.

21. Oliver Rackham, The History of the Countryside (London: J. M. Dent, 1986), 86.

22. For example, if research demonstrated that restoring a degraded coppice woodland by instigating a 20-year felling cycle instead of the traditional 8-15 is ideal for the (rare) common dormouse (Muscardinus avellanarius), then the restoration of biodiversity value would come into conflict with the restoration of cultural heritage value. 
23. Janna Thompson, "Environment as Cultural Heritage," Environmental Ethics 22, 244.

Subsequent page numbers in the text refer to this article.

24. O’Neill, Ecology, 28.

25. O’Neill , Ecology, 30-31.

26. O’Neill , Ecology, 30-31.

27. Thompson, "Environment", 249.

28. Low population mobility, strong filial ties and, up to the Middle Ages, a feudal system which bound peasants to particular estates, mean that most cultural ecosystems will have been worked by the same families and communities for many generations. Even though the vast majority of our predecessors would not have owned any portion of the cultural ecosystems in which they worked and resided, it seems likely that they would nonetheless have valued them as their inheritance from their predecessors and as a legacy to their successors.

29. Many extant heathlands in the UK date from the Neolithic (5000 - 4000BP) and Bronze Age (3600 - 3000BP) (Dolman and Land, "Lowland Heathland," 268); coppice woodlands from the early Neolithic (Rackham, History, 321.); and reedbeds from the Bronze Age or Middle Ages (Rackham, History, 387).

30. See for example the numerous place names incorporating references to heathland in Rackham , History, 287.

31. For a fuller account of the cultural relationships human communities have formed with species and ecosystems, see Paul Knights, "Native Species, Human Communities and Cultural Relationships," Environmental Values 17 (2008): 352-72.

32. O’Neill, Ecology, 33.

33. J. Sheail, J. R. Treweek and J. O. Mountford, "The UK transition from nature preservation to 'creative conservation'," Environmental Conservation 24 (1997): 232.

34. Richard Scott and Grant Luscombe, "Creative Conservation: A Way Forward," ECOS 16 (1995): 14

35. This assumption - that our predecessors had inadvertently, despite it forming no part of their motivations and, indeed, in many cases being inimical to their interests, discovered just how to manage ecosystems in a way that maximised their biodiversity value - may have seemed reasonable to the founders of the conservation movement in the early-to-mid 20th century. They had inherited the rapture with which 
18th and 19th century natural historians had described the very cultural ecosystems which were rapidly being lost to the depauperate landscapes of intensive, mechanised agriculture. Creative conservation is the result of the recognition that since traditional management was "[d]esigned to exploit rather than conserve" it may well be the case that many "species... [have] survived despite, rather than because of, such practices". (Sheail et. al., "The UK transition," 231). See also C. Hambler and M. R. Speight, "Biodiversity Conservation in Britain: Science Replacing Tradition,” British Wildlife 6 (1995): 137-47 and Rob Jarman, “Habitat Restoration - Recanting the Status Quo,” ECOS 16 (1995): 29-38.

36. See Peter Taylor, Beyond Conservation: A Wildland Strategy (London: Earthscan, 2005) for an overview of rewilding projects in the UK and Alan Watson Featherstone, "Rewilding in the north-central Highlands - an update," ECOS 25 (2004): 4-10 for an account of a large rewilding project in the Scottish Highlands. See also C. Donlan, Josh, Joel Berger, Carl E. Bock, Jane H. Bock, David A. Burney, and James A. Estes, Dave Foreman, Paul S. Martin, Gary W. Roemer, Felisa A. Smith, Michael E. Soulé and Harry W. Greene, “A Pleistocene Rewilding: An Optimistic Agenda for Twenty-First Century Conservation,” American Naturalist 168 (2005): 660-81 for a bold (Pleistocene) rewilding proposal for the US.

37. This recent recognition of the importance of top-down regulation has led to a reassessment of the orthodox view that top predators are relatively unimportant elements of natural systems. (Dave Foreman, Rewilding North America. London: Island Press, 2004), 119-124.) 